\title{
COUPLING OF NUMERICAL MODELS OF MESH GENERATION AND HEAT TRANSFER OF A TREE TRUNK IN A FOREST FIRE ENVIRONMENT
}

\author{
EUSÉBIO CONCEIÇÃO * , JOÃO GOMES ${ }^{\dagger}$, M. MANUELA LÚCIO * , JORGE \\ RAPOSO $^{\dagger \dagger}$, DOMINGOS VIEGAS ${ }^{\dagger \dagger}$ AND M. TERESA VIEGAS ${ }^{\dagger \dagger}$ \\ * Faculdade de Ciências e Tecnologia \\ Universidadedo Algarve \\ Campus de Gambelas, 8005-139 Faro, Portugal \\ e-mail: econcei@ualg.pt,maria.manuela.1ucio@gmail.com \\ ${ }^{\dagger}$ CINTAL \\ Universidade do Algarve \\ Campus de Gambelas, 8005-139 Faro, Portugal \\ email: jgomes@ualg.pt \\ ${ }^{\dagger}$ Faculdade de Ciências e Tecnologia \\ Universidade de Coimbra \\ Pólo II, Pinhal de Marrocos, 3030-290 Coimbra, Portugal \\ email: rafahunstman@hotmail.com; xavier.viegas@dem.uc.pt; maria.viegas@dem.uc.pt
}

Key words:Forest Fire, Numerical Simulation, Mesh Generation, Thermal Response, View Factor.

\begin{abstract}
This work presents a coupling between two numerical models, one for mesh generation and the other for heat transfer analysis, used to characterize the tree trunk thermal behaviour located in a forest fire environment. The geometry of the tree trunk is developed, using adaptive mesh generation, to evaluate the view factors, used to calculate the heat exchanges by radiation, between the virtual trunk tree and a fire front. The fire front represents the existing forest fire. The trunk tree thermal behavior numerical model is based on energy equations. The energy balance integral and differential equations consider the heat exchange by conduction inside the trunk tree, the heat exchange by convection between the trunk tree external surfaces and the environment and the heat exchanges by radiation between the trunk tree external surfaces and the environment and fire front. The numerical simulation is characterized by the propagation of a fire front at a constant fire spread rate of $0.01 \mathrm{~m} / \mathrm{s}$ from a distance of $5 \mathrm{~m}$ upstream of the tree trunk. With an irregular shape, the tree trunk has a height of $2 \mathrm{~m}$ and an external diameter of $0.2 \mathrm{~m}$. The fire front has a tilt angle of $45^{\circ}, 10 \mathrm{~m}$ wide and $2 \mathrm{~m}$ high. The temperature distribution in the tree trunk was obtained for a wind speed of $0.1 \mathrm{~m} / \mathrm{s}$, an average flame temperature of $500^{\circ} \mathrm{C}$, an environmental air temperature of $20^{\circ} \mathrm{C}$ and an air relative humidity around the trunk tree of $50 \%$. The temperature distribution obtained allows to identify the areas of the tree trunk tissues that were most affected by the passage of fire.
\end{abstract}




\section{INTRODUCTION}

Forest fires can cause significant changes on ecosystems. Its impacts have been increasing as the global temperature has increased due to climate change [1]. The fire front intensity and spread rate are two important fire behavior parameters. According to Blauw et al. [2], the moisture content, three-dimensional arrangement and mass of the fuel are the most important drivers of the fire spread and intensity of a forest fire. Forest fires can be divided into three categories, namely, crown fires, lethal understory fires and surface fires. Crown fires are relatively rare, but have higher severity and propagation spread rate than lethal understory and surface forest fires [3]. The tree flammability properties affect the tree response to fire. Its chance of survival reduces with increased flammability. Frejaville et al. [4] haveshownthatthebarkflammability of a tree reduces the potencial fortreesurvivalfollowingsurfacefires. Therefore, thebarkmust be slightlyflammableiftreeresistance to fireisprovidedby a thickinsulatingbark [4]. Experimentally, Jervis and Rein [5] investigated the differences in fire dynamics between live and dead Pinus needles. They concluded that not only moisture content is important in the burning behaviour of pine needles but also its chemistry and drying [5].

The numerical model of the tree trunk thermal response applied in this work is based on the numerical model of the human body thermal response. Both numerical models use energy balance equations in a similar way. The application of the numerical model of the human al. $[7,8]$

\section{The adaptive mes}

equations that simulate

energy balance equation

heat transfer processes: by conduction inside
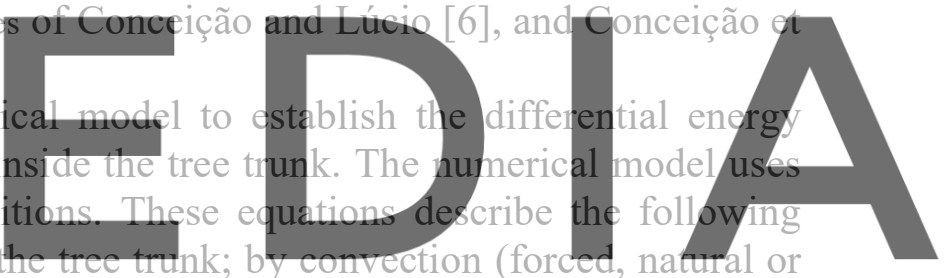

mixed) between the surface (bark) of the tree trunk and the surrounding environment; and by

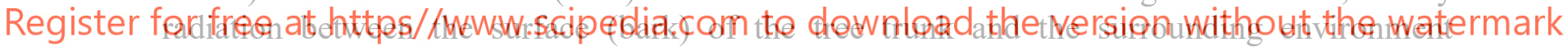

(including the fire front). The radiative exchanges between the tree trunk and the surrounding environment (including the fire front) are calculated using view factors. The procedure of this calculation is similar to that used to calculate heat exchanges inside the compartments. The model for calculating heat exchanges using view factors is one of the sub-models of the numerical model that evaluates the thermal response of buildings [9-16], and in the numerical model that evaluates the thermal behavior of passenger car cabinets [17].

The evaluation of the thermal response of a tree trunk located in a forest fire environment is done in this work. The objective is to characterize the level of damage of the tree's tissues by obtaining the distribution of temperatures on the surface and inside the tree trunk. The simulated situation considers a forest fire represented by a constant speed moving fire front. The fire front is moving towards the trunk tree, crossing it after a certain time.

\section{NUMERICAL MODEL}

The numerical model of this work is based on a coupling between two numerical models, one for mesh generation and the other for heat transfer analysis, used to characterize the tree trunk thermal behaviour located in a forest fire environment. 
The results of the numerical simulation are influenced by the type of mesh used. In this work, it is used a mesh generation to adapt the body surface contours of the tree trunk. This adaptation is done using the method of finite differences [18]. The adaptive mesh generation consists of transforming the physical domain into a computational domain, which is done by two elliptic partial differential equations, of Poisson's type. The adaptive grid generation used in this work can be seen in Figure 1.

The mesh generation is used to calculate the heat exchanges between the fire front and the trunk tree through view factors. The following thermal phenomena are considered for the tree trunk: heat conduction within the tree; heat convection between the tree surface and the environment; and heat exchange by radiation between the tree surface and the surroundings (fire front, fuel bed, sky). The following hypothesis are used to define the energy balance equations:

- The heat flux is two-dimensional;

- The air temperature around the tree trunk is uniform and the same as the environment temperature;

- Use of convection heat transfer coefficients developed for isothermal surfaces;

- The tree trunk is composed by bark and cambium;

- The action of fire around the tree is not considered.

This model has the following input data: wind speed; environmental temperature; fire front conditions (dimension initial distance of the
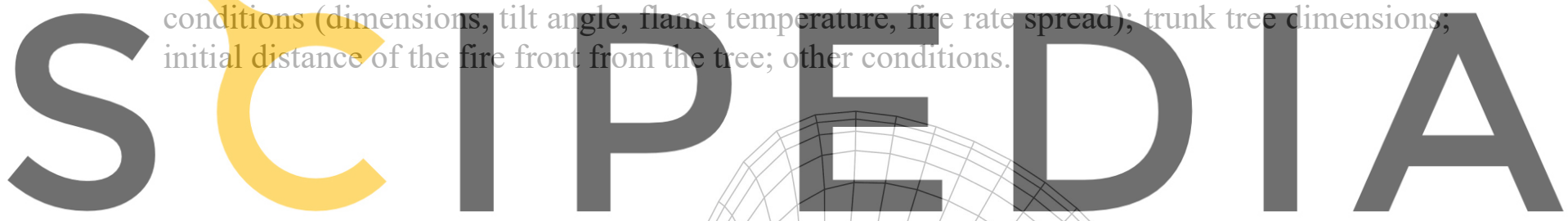

Register for free at https//wwwe scipedia.com to download the version without the watermark

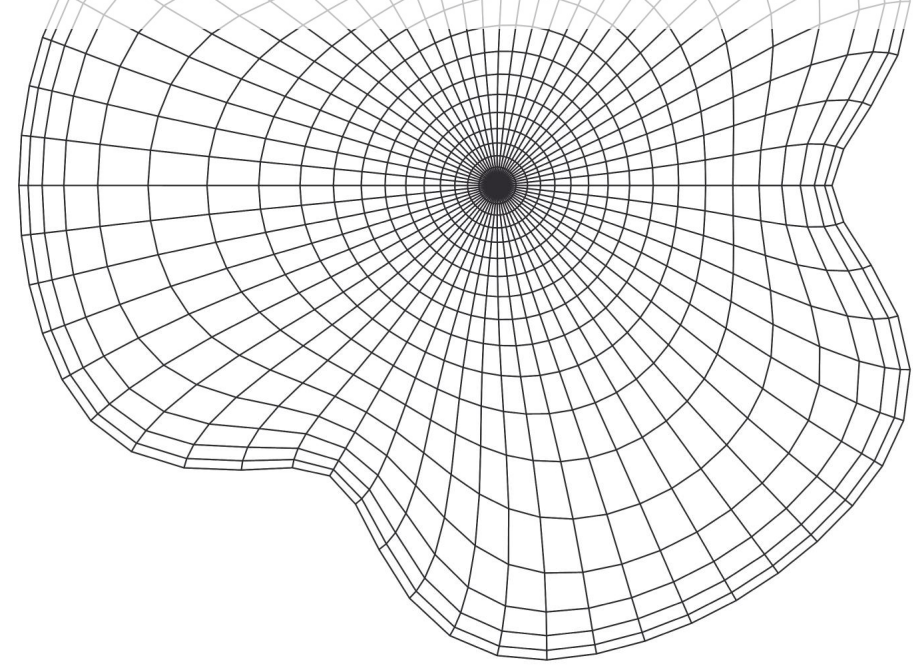


Figure 1: Adaptive grid generation used in the tree trunk $(61 \times 20$ grid points $)$.

\section{NUMERICAL METHODOLOGY}

The numerical simulation is characterized by the propagation of a fire front at a constant fire spread rate of $0.01 \mathrm{~m} / \mathrm{s}$ from a distance of $5 \mathrm{~m}$ upstream of the tree trunk. With an irregular shape, the tree trunk has a height of $2 \mathrm{~m}$ and an external diameter of $0.2 \mathrm{~m}$. The fire front has a tilt angle of $45^{\circ}, 10 \mathrm{~m}$ wide and $2 \mathrm{~m}$ high. The temperature distribution in the tree trunk was obtained for a wind speed of $0.1 \mathrm{~m} / \mathrm{s}$, an average flame temperature of $500^{\circ} \mathrm{C}$, an environmental air temperature of $20^{\circ} \mathrm{C}$ and an air relative humidity around the trunk tree of $50 \%$. The temperature distribution was obtained in a plane that cuts the tree at a height of $2 \mathrm{~m}$ at 61 points $(\mathrm{P})$ equidistant distributed along the external surface (bark) of the tree trunk and at 20 points $(\mathrm{Q})$ distributed along the radius of the tree trunk, as it is shown in Figure 2.

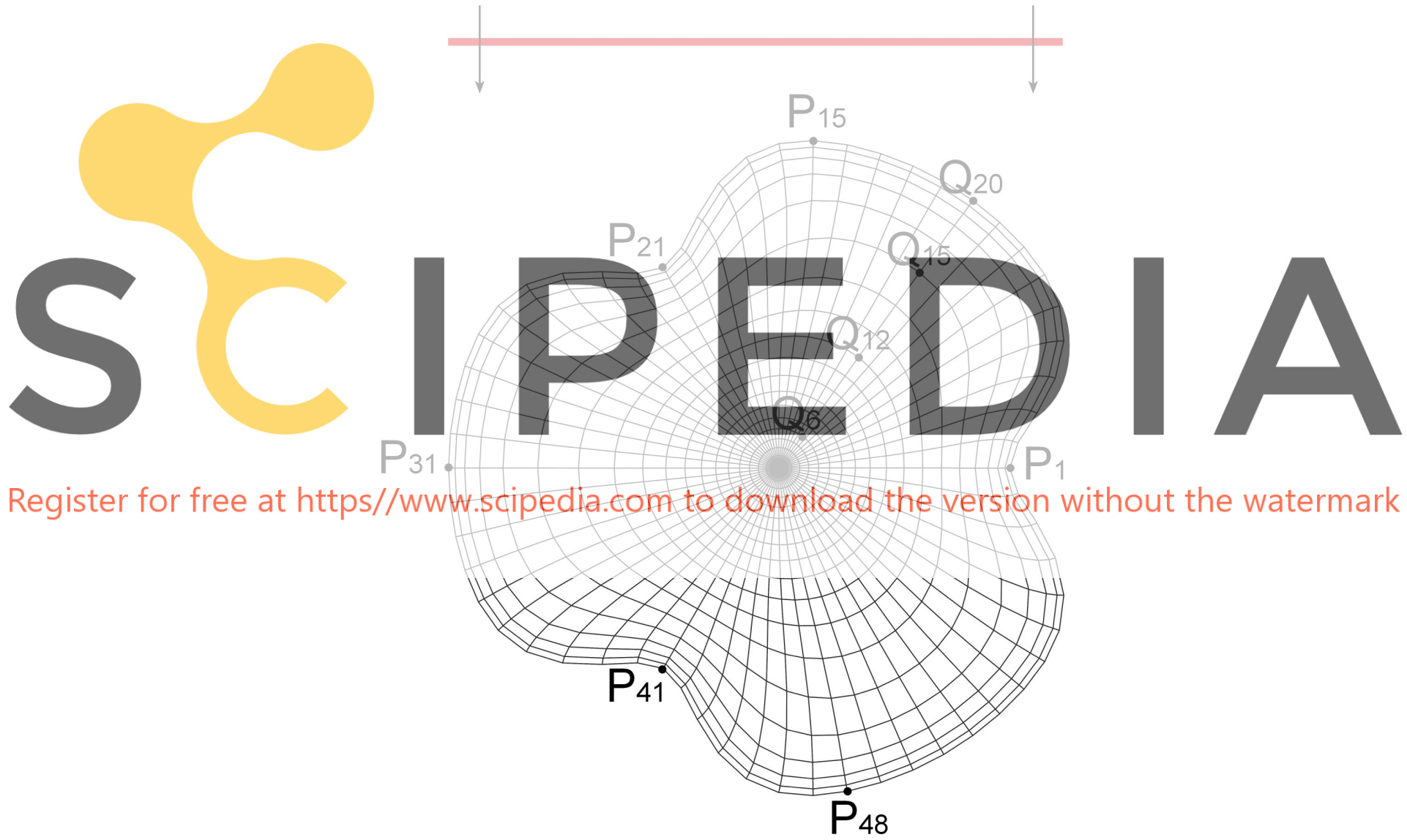

Figure 2: Location of the $61 \mathrm{P}$-points equidistant distributed along the bark of the tree trunk and the 20 Q-points distributed along the radius of the tree trunk. The red line represents the fire front.

\section{RESULTS AND DISCUSSION}

The evolution of the temperature distribution in the tree trunk, over time, is presented in Figure 3. In the initial instant, the fire front is $5 \mathrm{~m}$ upstream of the tree trunk.

The results show that the sections of the tree trunk most affected by the moving fire are 
mainly situated on the surface (bark and outermost ring). The highest temperatures are reached after around $400 \mathrm{~s}$ when the fire comes from the upstream side of the tree trunk, due to the inclination of the fire front. The temperatures are lower on the downstream side of the tree trunk due to the radiative exchanges with the fire front are of small amplitude. The lateral sections of the tree trunk are also little influenced by the moving fire, because the heat exchanges by conduction between the surface and the interior of the tree trunk are of little value. The cooling period is slower than the heating period, being longer on the upstream side than on the downstream side of the tree trunk. The lateral sections of the tree trunk have almost cooled down to close to $20^{\circ} \mathrm{C}$ at the end of $1800 \mathrm{~s}$.

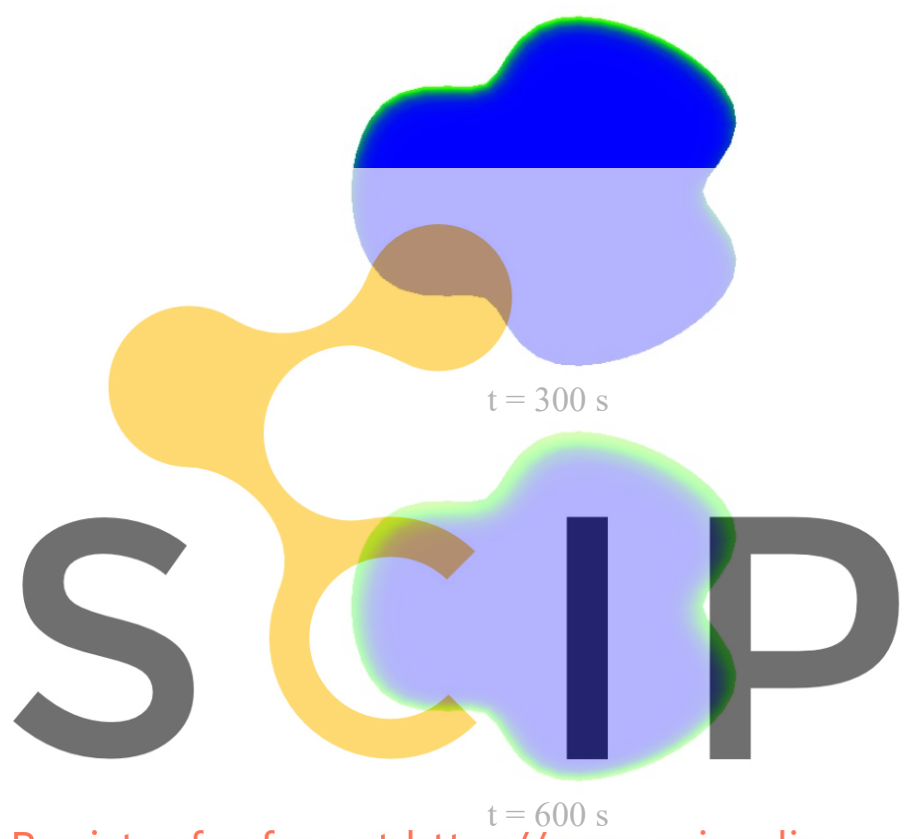

Register for free at https//www.scipedia.com
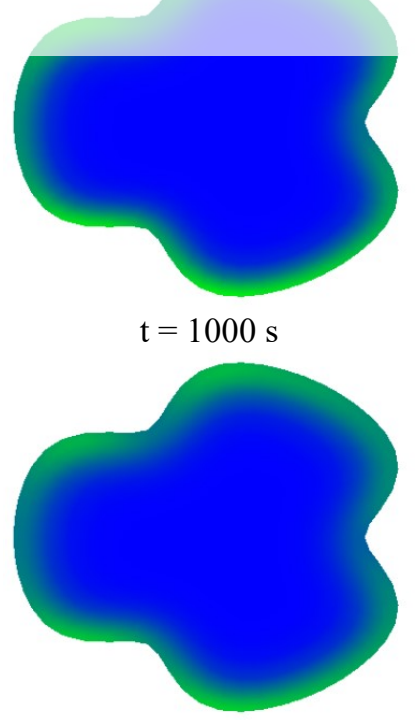
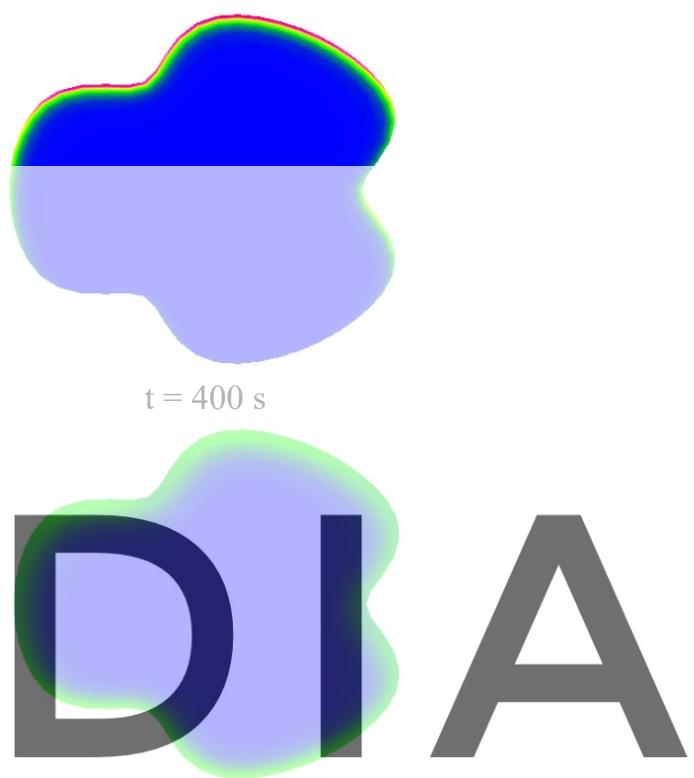

$t=800 \mathrm{~s}$
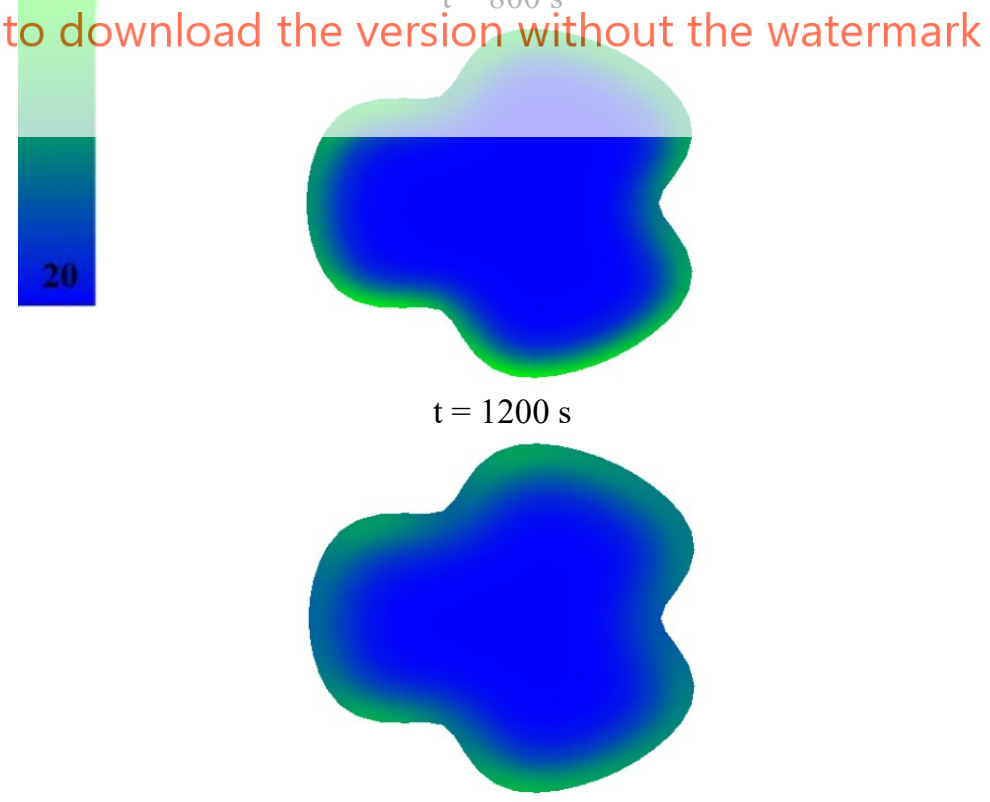


$$
\mathrm{t}=1400 \mathrm{~s} \quad \mathrm{t}=1800 \mathrm{~s}
$$

Figure 3: Evolution of the temperature distribution in the tree trunk.

The evolution of the temperature values obtained at selected P-points of the tree trunk is presented in Figure 4. In Figures 5 to 7, it is presented the evolution of the temperature at the points Q1-Q20 located on the line of the tree trunk radius which contains the selected P-points number 1, 15, 21, 31, 41 and 48 .

$$
\begin{array}{ll}
-\mathrm{P} 1 & -\mathrm{P} 15 \\
-\mathrm{P} 21 & -\mathrm{P} 31 \\
-\mathrm{P} 41 & -\mathrm{P} 48
\end{array}
$$

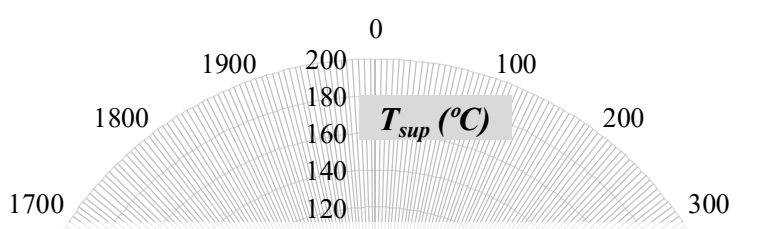

00
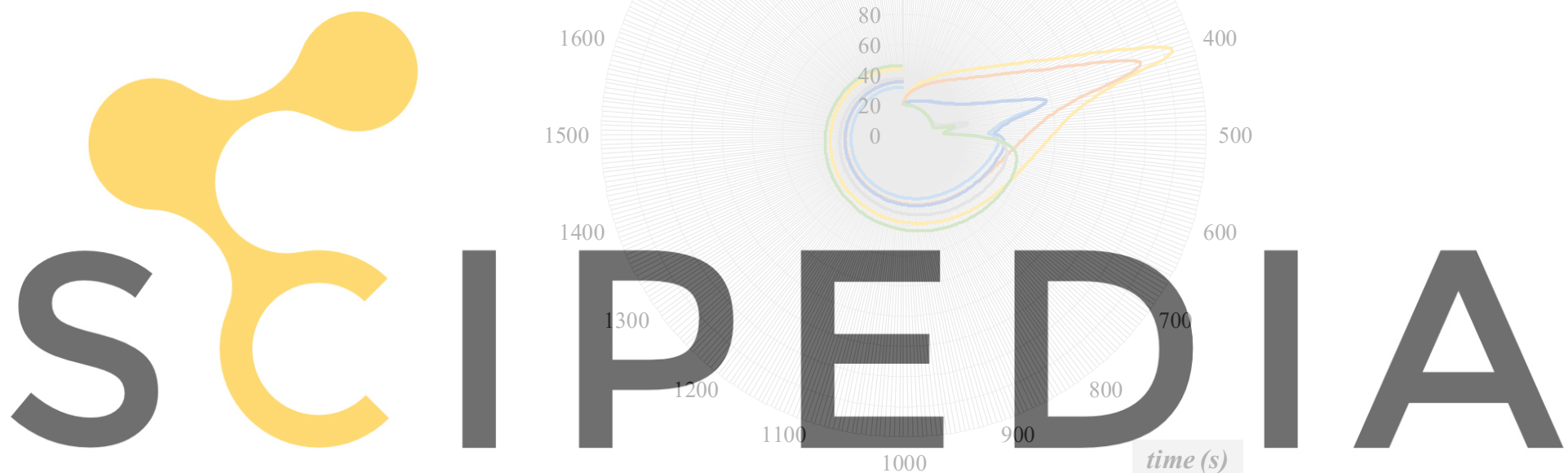

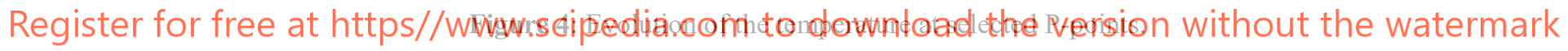

Regarding to the results, the temperature reaches higher values in the tree trunk bark upstream of the fire front than downstream of the fire front. The highest temperature of about $190^{\circ} \mathrm{C}$ is reached at the point $\mathrm{P} 15$ in the bark of the pine tree trunk facing upstream of the fire front. This value is obtained about $400 \mathrm{~s}$ of simulation time. Downstream of the tree trunk, the maximum temperature value of around $77^{\circ} \mathrm{C}$ is obtained at point $\mathrm{P} 48$ after about $600 \mathrm{~s}$ of simulation time. At the end of the simulation time $(2000 \mathrm{~s})$, the temperature in the bark of the tree trunk tends to values around $30-40^{\circ} \mathrm{C}$.

Inside the pine tree trunk, the temperature reaches higher values at its outermost points. In general, temperatures take values above $60^{\circ} \mathrm{C}$ in the two or three outermost rings. These values occur for about $700 \mathrm{~s}$ for the most adverse situations. In the outermost ring, the maximum temperature of around $112^{\circ} \mathrm{C}$ is obtained after $430 \mathrm{~s}$ of simulation time. At the end of the simulation time, all temperatures inside the tree trunk are below $40^{\circ} \mathrm{C}$. 


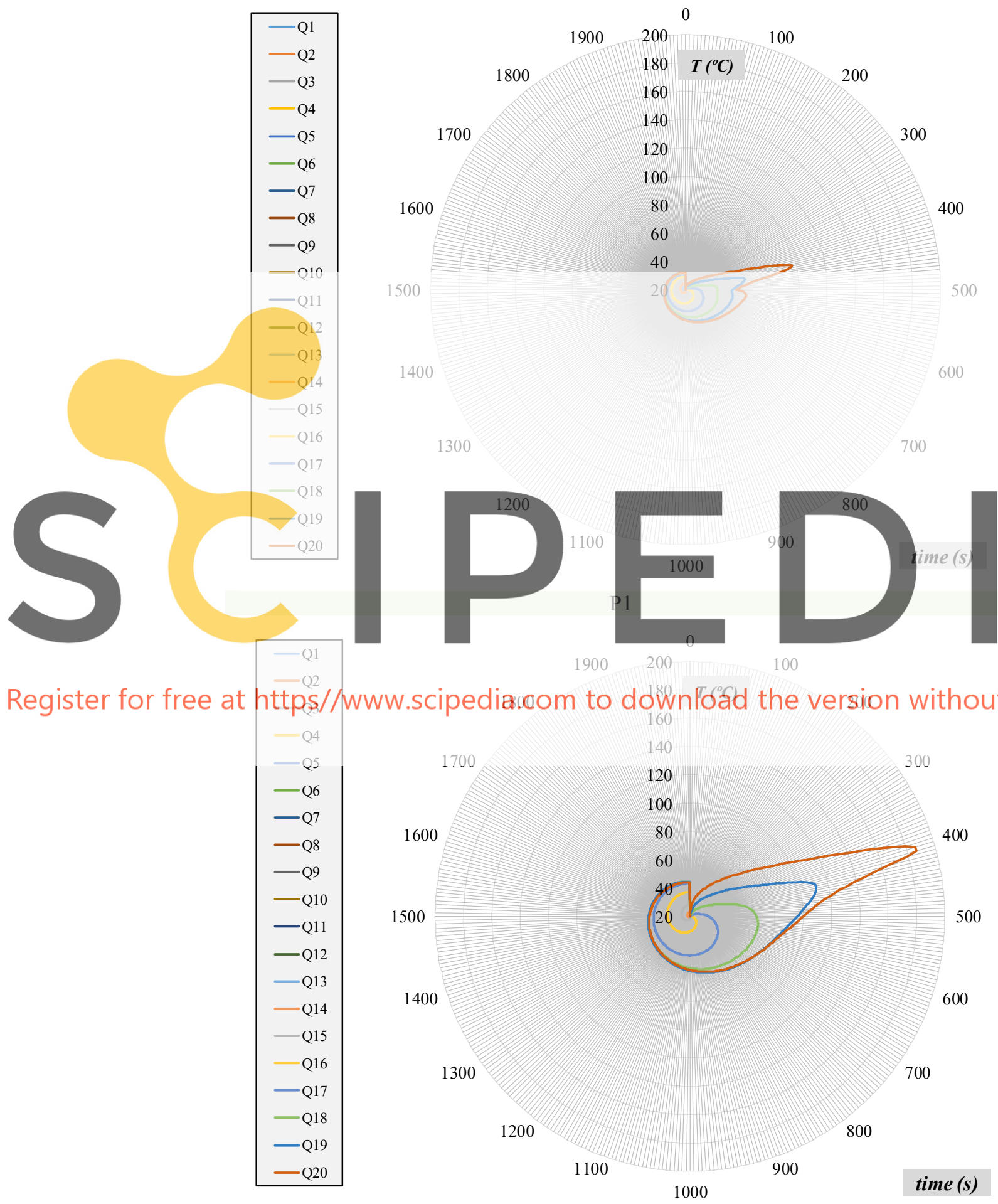




\section{P15}

Figure 5: Evolution of the temperature at the points Q1-Q20 located on the line of the tree trunk radius which contains the selected P-points 1 and 15
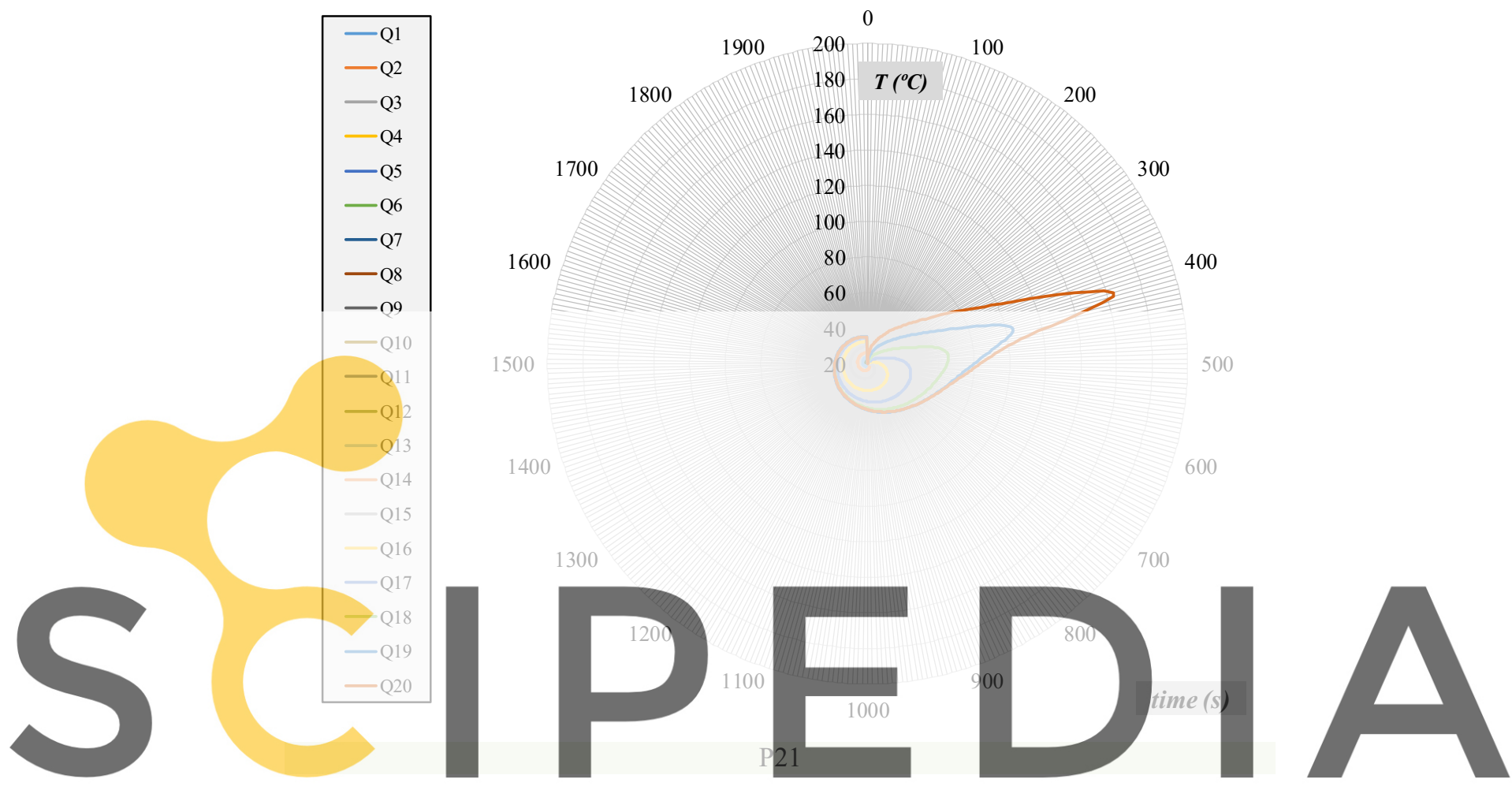

Register for free at https//www.scipedia.com to download the version without the watermark 


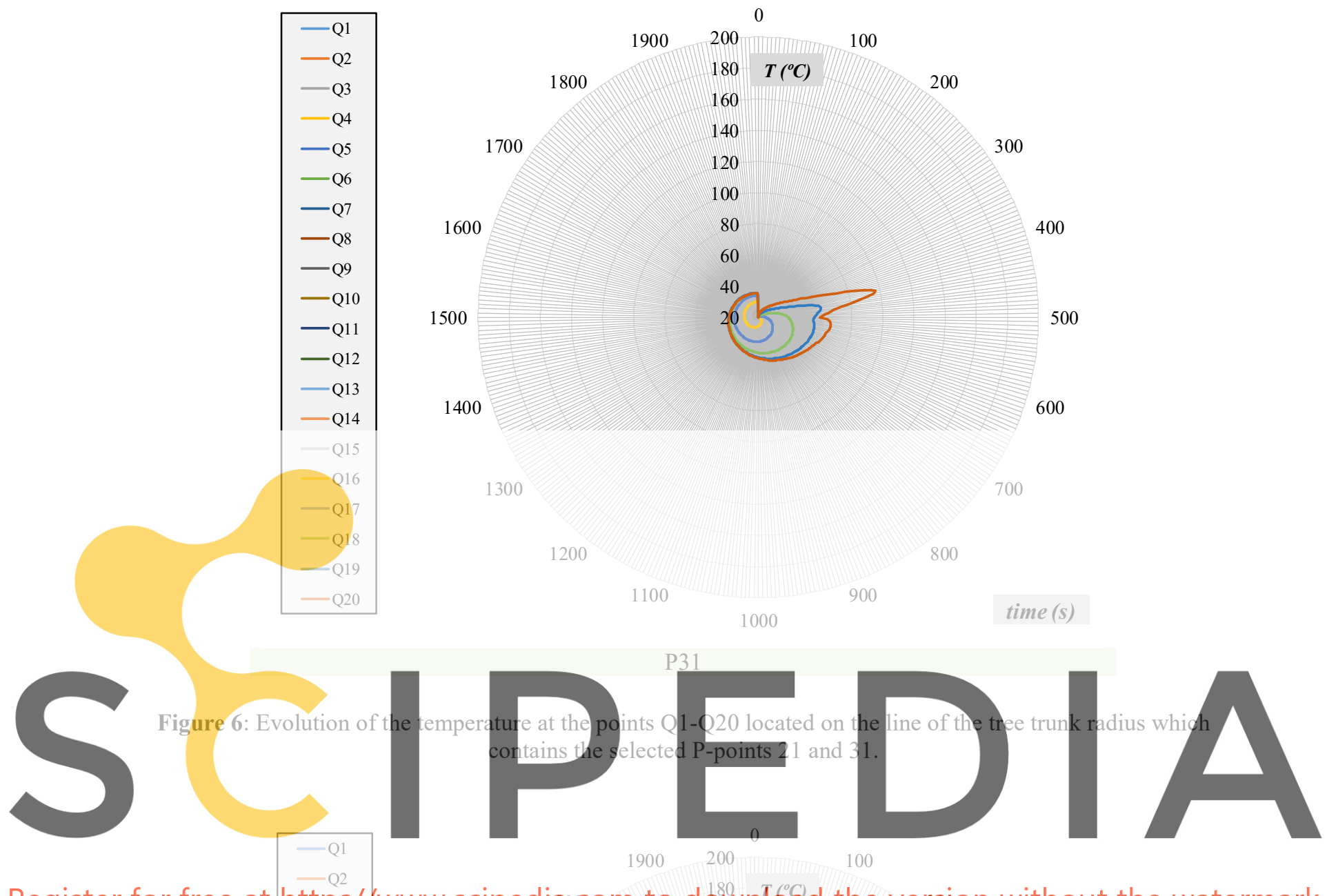

Register for free at https//www.scipedia.com to downitod the version without the watermark

$$
\begin{aligned}
& -\mathrm{Q} 5 \\
& -\mathrm{Q} 6 \\
& -\mathrm{Q} 7 \\
& -\mathrm{Q} 8 \\
& -\mathrm{Q} 9 \\
& -\mathrm{Q} 10 \\
& -\mathrm{Q} 11 \\
& -\mathrm{Q} 12 \\
& -\mathrm{Q} 13 \\
& -\mathrm{Q} 14 \\
& -\mathrm{Q} 15 \\
& -\mathrm{Q} 16 \\
& -\mathrm{Q} 17 \\
& -\mathrm{Q} 18 \\
& -\mathrm{Q} 19 \\
& -\mathrm{Q} 20
\end{aligned}
$$

1700

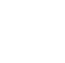

1500

1400

1300
140

120

100

80

60

40

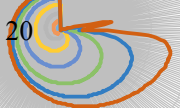

600

700

800

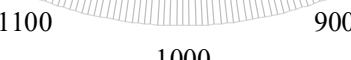

1000

time (s) 


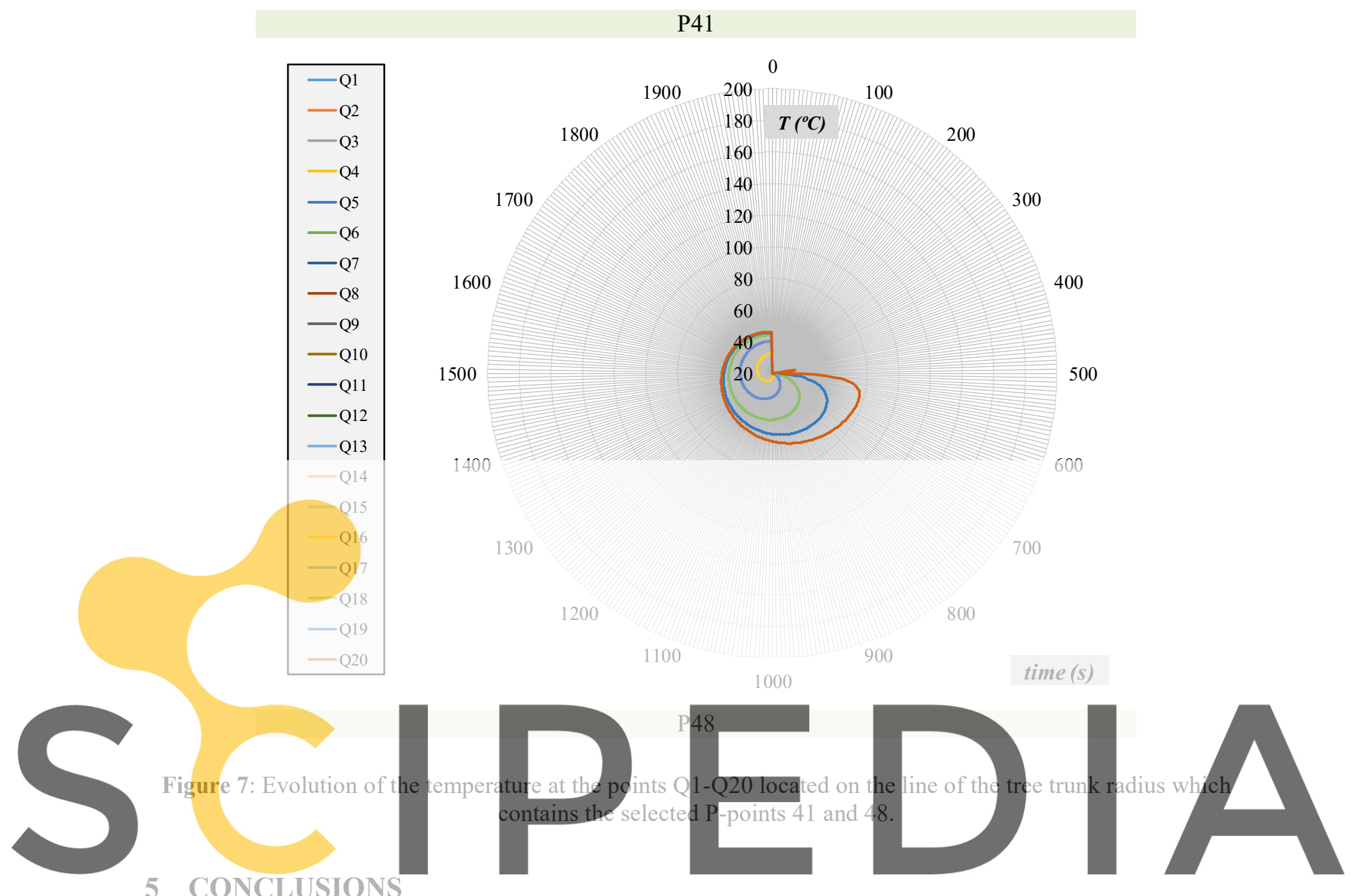

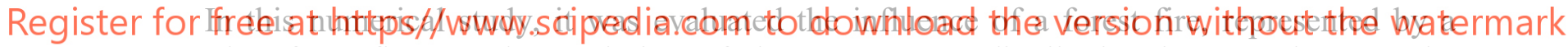
moving front fire, on the evolution of the temperature distribution in a trunk tree. The numerical simulation takes place over a period of time in which the fire front moves in the direction of the tree trunk from an initial position located $5 \mathrm{~m}$ downstream.

The results obtained for the temperature distribution show that the main sections of the trunk tree affected by the moving front fire are the bark and the two outermost rings. Due to the inclination of the flame, the upstream side reaches higher temperatures than the downstream side.

\section{ACKNOWLEDGEMENT}

The authors would like to acknowledge the support of the project reference PCIF/MPG/0108/2017, funded by the Portuguese Foundation of Science and Technology (FCT).

\section{REFERENCES}

[1] IPCC. Climate Change 2013: The Physical Science Basis. Contribution of Working Group I to the Fifth Assessment Report of the Intergovernmental Panel on Climate Change. 
Cambridge University Press, Cambridge, United Kingdom (2013).

[2] Blauw; L., van Logtestijn, R., Broekman, R., Aerts, R. and Cornelissen, J. Tree species identity in high-latitude forests determines fire spread through fuel ladders from branches to soil and vice versa. Forest Ecol. Manag.(2017) 400:475-484.

[3] Kim, D., Chung, W. and Lee, B. Exploring tree crown spacing and slope interaction effects on fire behavior with a physics-based fire model. Forest Sci. Technol. (2016) 12(4):167-175.

[4] Frejaville, T., Curt, T. and Carcaillet, C. Barkflammability as a fire-response traitforsubalpinetrees. Front. PlantSci. (2013) 4:466.

[5] Jervis, F. and Rein, G. Experimental study on the burning behaviour of Pinushalepensis needles using small-scale fire calorimetry of live, aged and dead samples. Fire Mater. (2016) 40:385-395.

[6] Conceição, E. and Lúcio, M. Numerical simulation of the application of solar radiant systems, internal airflow and occupants' presence in the improvement of comfort in winter conditions. Buildings (2016) 6(3):38.

[7] Conceição, E., Rosa, S., Custódio, A., Andrade, R., Meira, M. and Lúcio, M. Study of airflow around occupants seated in desks equipped with upper and lower air terminal devices for slightly warm environments. HVAC\&R Res. (2010)16(4):401-412.

[8] Conceição, E., Lúcio, M. and Awbi, H. Comfort and airflow evaluation in spaces equipped with mixing ventilation and cold radiant floor. Build. Simul. (2013) 6:51-67.

[9] Conceição, E. and Lúcio, M. Numerical study of thermal response of school buildings in summer conditions. HB 2006 -Healthy Buildings: Creating a Healthy Indoor Environment for People, Proceedings (2006) 3:195-200.

[10]Conceição, E. and Lúcio, M. Numerical study of the thermal efficiency of a school building with complex topology for different orientations. Indoor Built Environ. (2009) 18:41-51.

[11]Conceição, E. and Lúcio, M. Numerical simulation of passive and active solar strategies in building with complex topology. Build. Simul. (2010) 3:245-261.

[12] Conceição, E. and Lúcio, M. Numerical study of the influence of opaque external trees with pyramidal shape in the thermal behaviour of a school building in summer conditions. Indoor Built Environ. (2010) 19:657-667.

[13] Conceição, E., Lúcio, M. and Lopes, M. Application of an indoor greenhouse in the energy and thermal comfort performance in a kindergarten school building in the south of Portugal in winter conditions. WSEAS Trans. Environ. Dev. (2008) 4:644-654.

[14]Conceição, E., Lúcio, M., Ruano, A. and Crispim, E. Development of a temperature control model used in HVAC systems in school spaces in Mediterranean climate. Build. Environ. (2009) 44:871-877.

[15] Conceição, E., Nunes, A., Gomes, J. and Lúcio, M. Application of a school building thermal response numerical model in the evolution of the adaptive thermal comfort level in the Mediterranean environment. Int. J. Vent. (2010) 9:287-304.

[16] Conceição, E., Gomes, J. and Ruano, A. Application of HVAC systems with control based on PMV index in university buildings with complex topology. IFAC PapersOnLine (2018) 51(10):20-25.

[17] Conceição, E., Silva, M., André, J. and Viegas, D. Thermal behaviour simulation of the passenger compartment of vehicles. Int. J. Veh. Des. (2000) 24(4):372-387. 
[18] Anderson, J.D. Computational Fluid Dynamics - The Basics with Applications. McGrawHill International Editions, Singapore (1995). 